\title{
PFC Dual Boost Converter Based on Input Voltage Estimation for DC Inverter Air Conditioner
}

\author{
Gwi-Geun Park*, Kee-Yong Kwon*, and Tae-Woong Kim ${ }^{\dagger}$ \\ ${ }^{\dagger}$ Dept. of Control and Instrumentation Eng., Gyeongsang National University, Jinju, Korea \\ * AC Control 2 Group, AC Control R\&D Lab, LG Electronics Inc., Changwon, Korea
}

\begin{abstract}
In this paper, a single-phase PFC (Power Factor Correction) dual boost converter based on input voltage estimation is studied for DC inverter air conditioner. It is focused on improving input power factor and power quality to satisfy the recent harmonic current regulation standards. Furthermore the input voltage estimation is introduced for price competitive products. A low cost and reasonable control system is implemented using a specified high-speed 32-bit microprocessor. Their effectiveness are verified through theoretical analysis and experiments.
\end{abstract}

Key Words: Dual boost converter, Power factor correction, Voltage estimation, DC inverter air conditioner, Harmonic current

\section{INTRODUCTION}

With the increase in use of HVAC (heating, ventilation, and air conditioning) systems, power demands have increased considerably. Thus global warming and various environmental problems have been accelerating the Kyoto-Protocol introduced in 1997, to prevent global warming by regulating carbon-dioxide emissions and minimizing energy consumption, has accelerated the trend for developing highly energy efficient products.

In particular, home appliances like air conditioners, washing machines, refrigerators, etc. are required to be eco-friendly and highly energy-efficient. As a result, need for energy efficient systems like inverter control system are increasing rapidly.

DC inverter air conditioner (named in the products of LG Electronics) using permanent magnet synchronous motor (IPMSM) consists of a converter, a DC-link circuit, and an inverter.

Harmonic currents and power factor of power grid are dependent on configuration of power conversion system and its control algorithm. Increased harmonic current and reduced input power factor adversely affect other electric equipments connected to power grid, thus causing these connected systems to malfunction and reducing lifetime. Therefore, many countries have introduced more forceful laws to regulate power quality.

In the EU, electrical products can't be marketed if they doesn't meet the IEC 61000-3-2 harmonic current regulation standards. Therefore products should adopt power conversion system that satisfy the harmonic current regulation standards.

Manuscript received Jan. 15, 2010; revised Apr. 6, 2010

† Corresponding Author: kimtw@gnu.ac.kr

Tel: +82-55-751-5373, Gyeongsang National University

* AC Control 2 Group, AC Control R\&D Lab, LG Electronics Inc., Korea
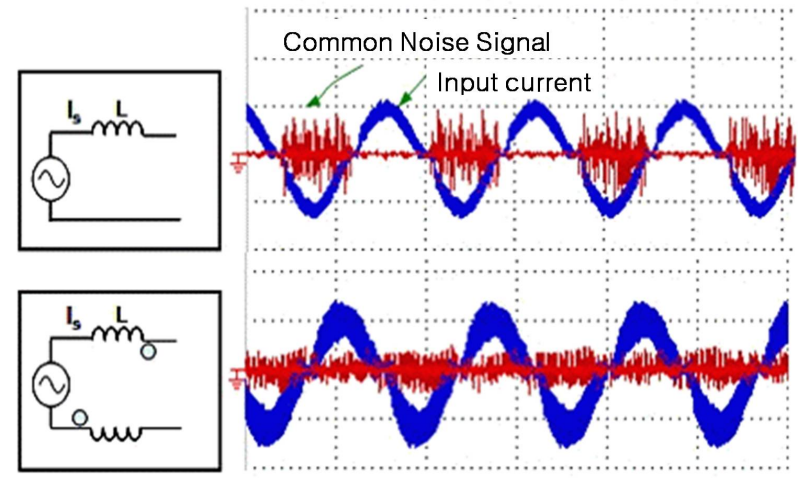

Fig. 1. Noise comparison according to installed position of inductor.

Minimizing harmonics in a power conversion system increases manufacturing costs. In order to minimize additional manufacturing costs, the most suitable design for power conversion system is required.

By analyzing common mode noise shown in Fig. 1, it can be seen that a dual boost converter (DBC) with power factor correction (PFC) should be optimized [1]. Furthermore problem of power quality caused by resonance of input LC filter should be solved [2]. These are important works to be treated and solved from power conversion system point of view. To improve input power factor and suppress total harmonic distortion, circuit configuration and algorithm [4], [5] need to be proposed. Introducing input voltage sensorless algorithm, where input voltage is estimated only via input current information, the cost cut of total system should be implemented. These are important factors to be considered for price-competitive home appliances [3], [6], [7].

In this paper, to solve these issues, single high-speed mi- 
croprocessor based on dual boost converter is used to control PFC, two inverters for fan and compressor. And also the dual boost converter with PFC for DC inverter air conditioner is implemented and tested. These possibilities have been verified through theoretical analysis and experiments.

\section{DC INVERTER AIR CONDITIONER}

\section{A. Configuration of control system}

DC inverter air conditioner is called total control system for IPMSM drive, and the entire system is briefly presented as follows.

As shown in Fig. 2, consider the case of commercial air conditioner (CAC) unit consisting of an indoor unit and an outdoor unit. A four-core cable is used for communication and power supply between indoor and outdoor units. As previously mentioned, a highly efficient air conditioner should be energyefficient and requires coefficient of performance (COP) 4.0 or above. To achieve high energy-efficiency, highly efficient IPMSM is used as compressor motor and fan motor, and also the size of heat exchanger should be well matched with the entire system.

The indoor unit has a microprocessor based control system to adjust the amount and the direction of air flows. It also has to display and receive the remote control signals. The outdoor unit has a microprocessor based control system to adjust compressor capacity, heat exchanger capacity, fan motor, power factor correction, and DC-link voltage regulation.

Induction motor, synchronous reluctance motor, brushless DC motor, and permanent magnet synchronous motor are generally used as compressor motor, but the use of IPMSM has increased due to its high efficiency. With the emergence of rare-earth magnets, IPMSM in high-end consumer electronics has been increasing thus realizing high efficiency electric appliances.

Fig. 2 shows commercially available DC inverter air conditioner, in which IPMSM is used as both fan motor for indoor unit and compressor motor for outdoor unit. DC inverter air conditioner has highly efficient product design. Only converter control among control systems of the outdoor unit is mentioned.

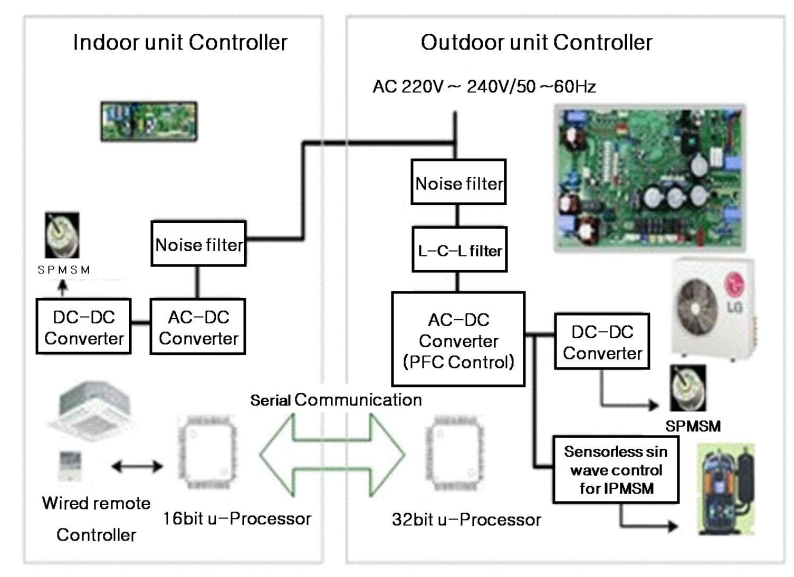

Fig. 2. Control system of CAC typed DC inverter air conditioner.

\section{B. Harmonic current regulations}

DC inverter air conditioner is categorized as an electric home appliance and should comply with IEC 61000-3-2 Class A regulations. Allowable maximum harmonic currents under IEC 61000-3-2 Class A regulations are shown in Table 1. Even though the power consumption is less than $600 \mathrm{~W}$, the permissible 3 rd harmonic current is $2.3 \mathrm{~A}$. Irrespective of consumption, all equipments must comply with the standards.

The input power factor (PF) can be expressed as the ratio of fundamental current to total input current as shown in (1).

$$
\mathrm{PF}=\frac{P}{S}=\frac{V_{s} V_{s 1} \cos \theta}{V_{s} I_{s}}=\frac{I_{s 1}}{I_{s}} \cos \theta
$$

where $P$ : active power, $Q$ : reactive power, $S:$ apparent power, $V_{s}$ : input voltage, $I_{s}$ : input current (total input current), $I_{s 1}$ : fundamental input current.

Fig. 3 shows the minimum input power factor required to comply with the regulations, under the given load current using (1) and Table 1.

To pass the environmental regulations shown in Fig. 3, the given input power factor under full load conditions should be satisfied. Under $7 A$ load conditions, $95 \%$ of input power factor should be at least satisfied. Furthermore, under more than $16 A$ load conditions, minimum $98 \%$ of input power factor should be satisfied. Therefore the most suitable method for power factor correction should be selected to satisfy the above conditions.

\section{Proposal of DUAL Boost CONVERTER WITH PFC CONTROL}

\section{A. System configuration}

The system configuration proposed in this paper is shown in Fig. 4 and it consists of the following; EMC filter, LCL filter with damping resistance to suppress resonance, converter with internal IGBT protection functions, DC-link circuit with capacitor between converter and inverter, and an inverter for driving compressor motor and fan motor. The overall system is controlled by a high speed microprocessor.

The conventional converter with PFC control in Fig. 5(a) requires a power diode with ultra fast recovery time characteristics, and includes safety problems and reliability issues.

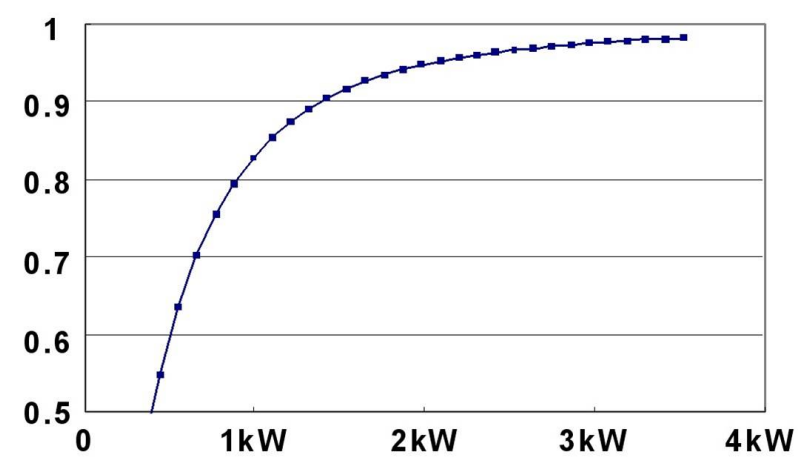

Fig. 3. Allowable power factor according to load conditions under harmonic current regulations; $\mathrm{x}$ axis(load power), $\mathrm{y}$ axis(power factor). 


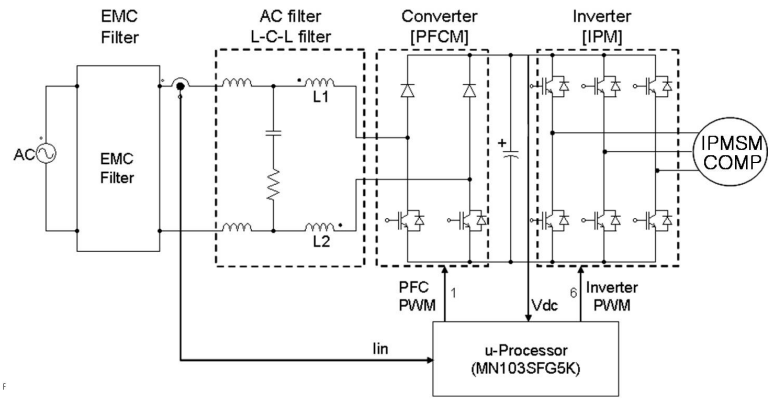

Fig. 4. Overall configuration for IPMSM drives and PFC control.

During mass production, static electricity of gate terminal is easily generated due to the use of separate IGBTs, and as a result its reliability goes down. In addition, compared with the PFC dual boost converter in Fig. 5(b), the conventional power conversion system has lower energy efficiency and the overall performance of air conditioner is deteriorated.

\section{B. Input voltage estimation algorithms}

Generally the feedbacked information such as input voltages, input currents, and DC-link voltage is required for power factor correction.

The input voltage estimation for single-phase half-bridge PWM rectifier presented in [6], [9]-[13], is newly applied to dual boost converter in Fig. 5(b) as enhanced topology.

Single phase PFC dual boost converter is based on the input voltage estimation, which estimates the phase angle and magnitude of supply voltage. The variation between detected current and model current should be controlled almost at zero for input voltage estimation.

It is shown in this paper that both magnitude and phase of input voltage can be estimated based on the error between actual current and model current. As the error is within the tolerance limit, correct magnitude and phase of input voltage can be estimated.

Voltage equation in Fig. 5(b) can be expressed as follows.

$$
v_{s}=V_{s} \cos \omega t
$$

Voltage-current equation for the proposed power conversion topology is expressed as follows.

TABLE I

LIMITS OF CLASS A EQUIPMENTS UNDER IEC 61000-3-2

\begin{tabular}{|c||c|c|}
\hline \multirow{4}{*}{$\begin{array}{c}\text { odd } \\
\text { harmonic }\end{array}$} & $\begin{array}{c}\text { order } \\
\text { number }\end{array}$ & $\begin{array}{c}\text { max. permissible } \\
\text { harmonic current }[A]\end{array}$ \\
\cline { 2 - 3 } & 3 & 2.30 \\
\cline { 2 - 3 } & 5 & 1.14 \\
\cline { 2 - 3 } & 9 & 0.77 \\
\cline { 2 - 3 } & 11 & 0.40 \\
\cline { 2 - 3 } even \\
harmonic & $13 \leq n \leq 39$ & 0.33 \\
\cline { 2 - 3 } & 2 & 0.21 \\
\cline { 2 - 3 } & 8 & $0.15 \times 15 / n$ \\
\hline \multirow{3}{*}{\begin{tabular}{c} 
han \\
\cline { 2 - 3 }
\end{tabular}} & 6 & 1.08 \\
\hline
\end{tabular}

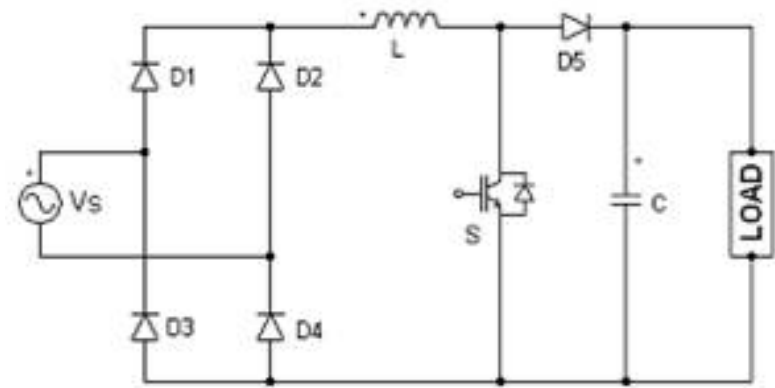

(a) conventional boost converter with PFC control.

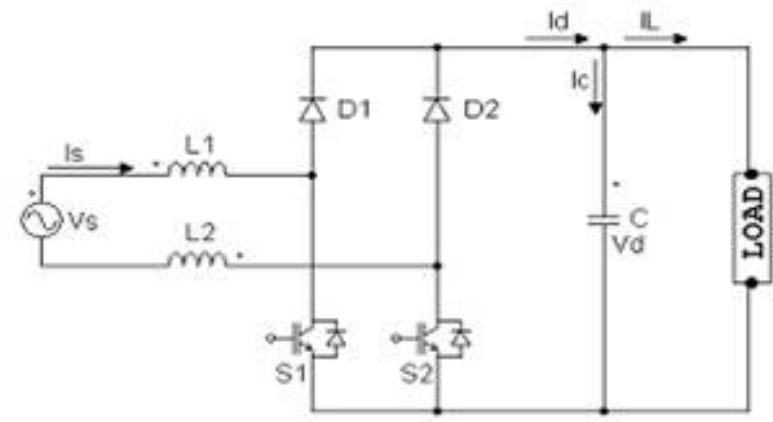

(b) proposed dual boost converter with PFC control.

Fig. 5. Boost power conversion system with PFC control.

$$
v_{s}=R_{s} i_{s}+L_{1} \frac{d i_{s}}{d t}+L_{2} \frac{d i_{s}}{d t}+V_{r}
$$

where $R_{s}$ is internal impedance of source voltage and $V_{r}$ is voltage across diode, dependant on the switching state (turn-on or turn-off) of IGBT.

$$
\begin{array}{lcl}
V_{r}= & 0 & \text { at turn-on state of IGBT } \\
V_{r}= & V_{d} & \text { at turn-off state of IGBT }
\end{array}
$$

The average voltage during one cycle is calculated as follows.

$$
V_{r}=(1-d) \cdot V_{d}
$$

(3) should be rewritten as differential equation of (5) for digitalization and implementation by microprocessor.

$$
\begin{aligned}
v_{s}[n-1]= & R_{s} \cdot i_{s}[n-1] \\
& +\frac{L_{1}+L_{2}}{T_{s}}\left(i_{s}[n]-i_{s}[n-1]\right)+V_{r}[n-1]
\end{aligned}
$$

where $T_{s}$ is current control period.

Furthermore, input voltage $v_{s}[n-1]$ can be expressed as follows under peak value $V_{s}$, angular frequency $\omega$, and initial phase angle $\theta_{0}$ at the time $[n-1]$.

$$
\begin{gathered}
v_{s}[n-1]=V_{s} \cos \theta_{s} \\
\theta_{s}[n]=\omega[n-1] T_{s}+\theta_{0}
\end{gathered}
$$

Input current $i_{s}$ can be expressed as; 


$$
\begin{aligned}
i_{s}[n]= & i_{s}[n-1]+ \\
& \frac{T_{s}}{L_{1}+L_{2}}\left(v_{s}[n-1]-R_{s} \cdot i_{s}[n-1]-V_{r}[n-1]\right)
\end{aligned}
$$

The estimated input voltage is expressed as;

$$
v_{\mathrm{M}}[n-1]=V_{\mathrm{M}} \cos \theta_{\mathrm{M}}
$$

where $v_{\mathrm{M}}$ : estimated voltage, $V_{\mathrm{M}}$ : maximum magnitude of estimated voltage, $\theta_{\mathrm{M}}$ : estimated phase.

Model equation of dual boost power conversion system is expressed in terms of inductance and resistance, and is given as below.

$$
\begin{aligned}
i_{\mathrm{M}}[n-1]= & i_{s}[n-1]+\frac{T_{s}}{L_{\mathrm{M} 1}+L_{\mathrm{M} 2}} \\
& \left(v_{\mathrm{M}}[n-1]-R_{\mathrm{M}} \cdot i_{s}[n-1]-V_{r}[n-1]\right)
\end{aligned}
$$

If inductance $L_{\mathrm{M}}$ and resistance $R_{\mathrm{M}}$ between actual dualboost system and model dual boost system are equal, the current error between actual current of (8) and model current of (10) can be expressed as below.

$$
\begin{aligned}
\Delta i_{s}[n] & =i_{s}[n]-i_{\mathrm{M}}[n] \\
& =\frac{T_{s}}{L_{1}+L_{2}}\left(v_{s}[n-1]-v_{\mathrm{M}}[n-1]\right) \\
& =\frac{T_{s}}{L_{1}+L_{2}} \Delta v
\end{aligned}
$$

The voltage error is expressed in terms of magnitude and phase error, which are expressed as.

$$
\begin{aligned}
\Delta v & =\left.\Delta V \frac{\partial\left(V \cos \theta_{s}\right)}{\partial V}\right|_{V_{\mathrm{M}}, \theta_{\mathrm{M}}}+\left.\Delta \theta \frac{\partial\left(V \cos \theta_{s}\right)}{\partial \theta}\right|_{V_{\mathrm{M}}, \theta_{\mathrm{M}}} \\
& =\Delta V \cos \theta_{\mathrm{M}}-\Delta \theta \cdot V_{\mathrm{M}} \sin \theta_{\mathrm{M}}
\end{aligned}
$$

Putting (12) into (11), (11) can be reexpressed as follows.

$$
\Delta i_{s}[n]=\frac{T_{s}}{L_{1}+L_{2}}\left(\Delta V \cos \theta_{\mathrm{M}}-\Delta \theta \cdot V_{\mathrm{M}} \sin \theta_{\mathrm{M}}\right)
$$

Using Fourier Series, voltage error $\Delta V$ and voltage phase error $\Delta \theta$ are expressed as;

$$
\begin{gathered}
\Delta V=\frac{L_{1}+L_{2}}{T_{s}}\left(\frac{1}{\pi} \int_{0}^{2 \pi} \Delta i_{s} \cos \theta_{\mathrm{M}} d \theta_{\mathrm{M}}\right) \\
\Delta \theta=\frac{L_{1}+L_{2}}{T_{s} V_{\mathrm{M}}}\left(\frac{1}{\pi} \int_{0}^{2 \pi} \Delta i_{s} \sin \theta_{\mathrm{M}} d \theta_{\mathrm{M}}\right) \\
V_{\mathrm{M}}[n]=V_{\mathrm{M}}[n-1]+K_{\mathrm{E}} \cdot \Delta i_{s}[n] \cos \theta_{\mathrm{M}}[n-1] \\
\theta_{\mathrm{M}}[n]=\theta_{\mathrm{M}}[n-1]+\omega T_{s}-K_{\theta} \Delta i_{s}[n] \sin \theta_{\mathrm{M}}[n-1]
\end{gathered}
$$

where $K_{\mathrm{E}}$ : current gain in model equation, $K_{\theta}$ : current phase gain in model equation.

\section{PFC Control Algorithm}

Several algorithms have been proposed to obtain the unity input power factor [5], [8], [13]. In this paper, the PFC control algorithm based on dual boost converter is proposed and implemented. To implement the proposed PFC control algorithm, input voltage, current and DC-link voltage are basically required.

Under on state of S1 or S2 in Fig. 6(b), voltage-current equation of dual boost converter can be expressed as;

$$
v_{s}-L_{1} \frac{d i_{s}}{d t}-L_{2} \frac{d i_{s}}{d t}=0
$$

And if S1 and S2 are turned off, voltage-current equation of dual boost converter is represented as;

$$
v_{s}-L_{1} \frac{d i_{s}}{d t}-L_{2} \frac{d i_{s}}{d t}-V_{d} \cdot \operatorname{sgn}\left(i_{s}\right)=0
$$

where $V_{d}$ is DC-link voltage, If input power factor is unity, the condition of $\operatorname{sgn}\left(v_{s}\right)=\operatorname{sgn}\left(i_{s}\right)$ should be satisfied.

Inductor voltage $V_{\mathrm{L}}$ is depending on switching voltage duty ratio $d$, and can be expressed as (4) in terms of input current variation $d\left|i_{s}\right|$ during current control time $T_{s}$.

$$
\begin{aligned}
V_{\mathrm{L}} & =\frac{T_{\mathrm{on}} v_{s}+T_{\mathrm{off}}\left[v_{s}-V_{d} \cdot \operatorname{sgn}\left(i_{s}\right)\right]}{T_{s}} \\
& =v_{s} \cdot d+\left[v_{s}-V_{d} \cdot \operatorname{sgn}\left(i_{s}\right)\right](1-d) \\
& =\left(L_{1}+L_{2}\right) \frac{d\left|i_{s}\right|}{d t}
\end{aligned}
$$

where $d=T_{\text {on }} / T_{s}$.

Rearranging (4) in terms of duty ratio, (5) is obtained,

$$
\begin{aligned}
d & =\frac{\left(L_{1}+L_{2}\right) \frac{d i_{s} \mid}{d t}-\left[v_{s}-V_{d} \cdot \operatorname{sgn}\left(i_{s}\right)\right]}{V_{d} \cdot \operatorname{sgn}\left(i_{s}\right)} \\
& =\frac{\left(L_{1}+L_{2}\right) \frac{d\left|i_{s}\right|}{d t}-\left[V_{s} \sin \omega t-V_{d} \cdot \operatorname{sgn}\left(i_{s}\right)\right]}{V_{d} \cdot \operatorname{sgn}\left(i_{s}\right)} \\
& =\left(1-\frac{V_{s}}{V_{d}}|\sin \omega t|\right)+\frac{\left(L_{1}+L_{2}\right) d\left|i_{s}\right|}{V_{d} T_{s}}
\end{aligned}
$$

The followings can be obtained through briefly arranging the above equations.

$$
\begin{gathered}
d=d_{n}+d_{c} \\
d_{n}=1-\frac{V_{s}}{V_{d}}|\sin \omega t| \\
d_{c}=\frac{\left(L_{1}+L_{2}\right) d\left|i_{s}\right|}{V_{d} T_{s}}
\end{gathered}
$$

where $V_{s}$ is maximum magnitude of input voltage and $\omega$ is angular frequency.

$$
d_{c}=K_{\mathrm{pc}} \cdot i_{\mathrm{err}}+K_{\mathrm{ic}} \int i_{\mathrm{err}} d t
$$

where $K_{\mathrm{pc}}$ and $K_{\mathrm{ic}}$ are proportional gain and integral gain of input power factor correction respectively.

The overall block diagram of proposed PFC control is shown in Fig. 6. Fig. 6 shows the unity PFC controller of 


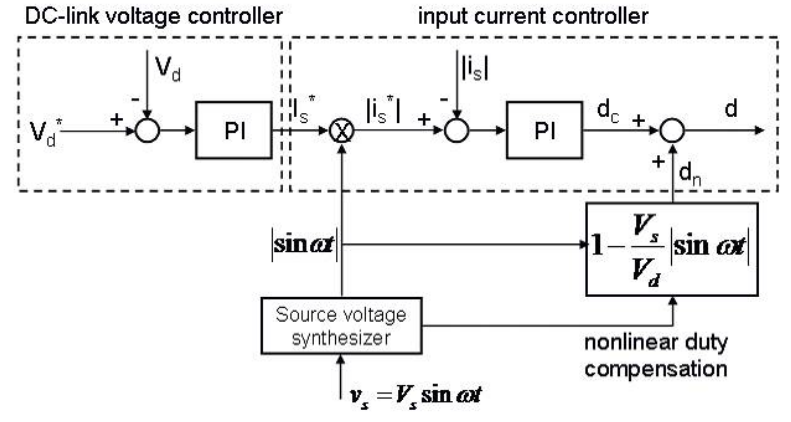

Fig. 6. Block diagram of proposed PFC control in dual boost converter.

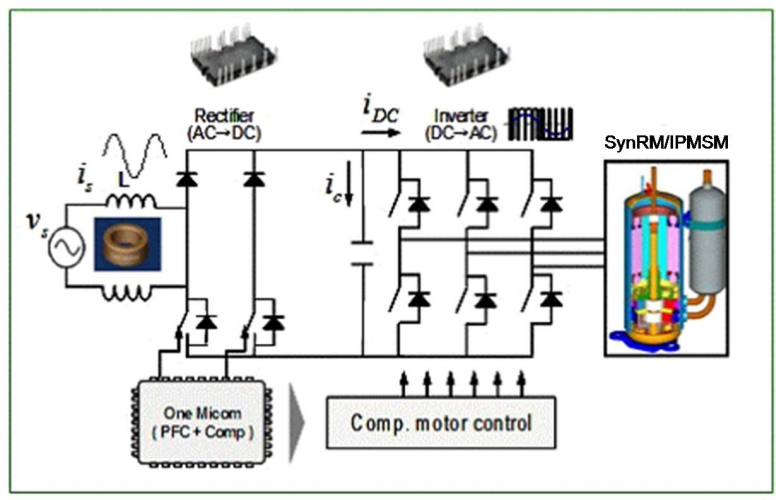

Fig. 7. Configuration of proposed DC inverter control system.

the dual boost converter. The output of current controller generates only the inductor voltage drop required to maintain the sinusoidal source current. With the addition of $d_{n}$ to the converter which is originally a nonlinear dynamic system, the relationship between $d_{c}$ and the output current of the converter becomes a first-order linear dynamic system in (24) with easy controllability. Thus, the addition of $d_{n}$ relaxes the burden of the PI current controller and improves the sources current waveform.

\section{EXPERIMENTS}

\section{A. System configuration}

The complete configuration of the proposed experimental system is shown in Fig. 7. Its configuration consists of $4 k W$ dual boost converter, inverter for 3-hp IPMSM compressor drive, and 32-bit RISC microprocessor. In detail, the experimental configuration is composed of the followings; EMI filter to overcome EMI issues, LCL filter for quality of commercial power grid, dual inductor with high flux core, converter with PFCM of Fairchild where temperature sensor and over-current protection are built-in, and inverter.

The design specifications of the proposed experimental system are listed in Table 2.

\section{B. Experimental results}

Fig. 8 shows the estimated input voltage by only sensing input current, and the actual input voltage. Due to scaling error, the estimated input voltage and the actual input voltage do not look same in this figure, but actually the estimated input

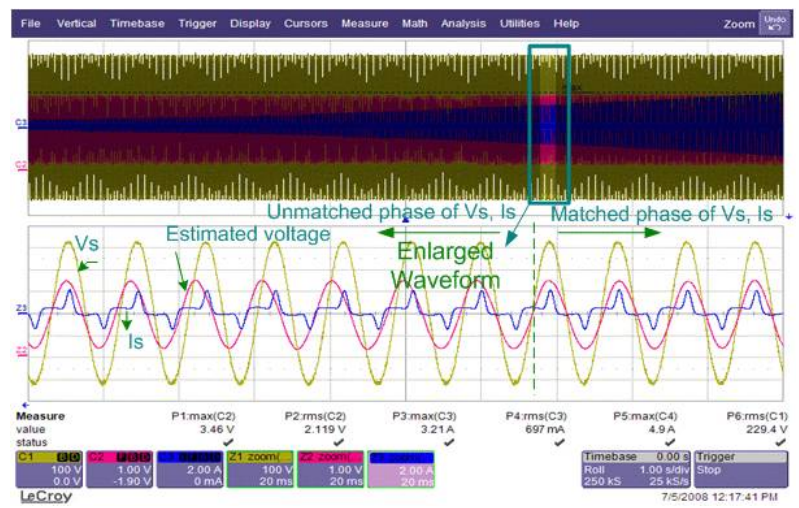

Fig. 8. Estimated voltage waveform on the basis of feedbacked input current information.

voltage is the same as the actual input voltage. Furthermore it can be confirmed that the phase between the estimated input voltage and the actual input voltage is equal. Under the initial conditions, the input voltage and input current is out of phase due to small value of input current, but for a little while the magnitude and the phase of input voltage can be accurately estimated.

Fig. 9 shows voltage and current at the applying point of PFC control. The input current in this figure is not filtered and PFC control is properly achieved to match the phase of actual input voltage.

Fig. 10 shows DC-link voltage, input current, and input voltage at $4 k W$ DC inverter control system respectively.

Fig. 11 shows experimental data when DC inverter control system operates at following conditions; Input current $18 \mathrm{~A}$, input power factor $99 \%$, compressor phase current $10.8 \mathrm{~A}$, and operating frequency $82 \mathrm{~Hz}$ for a power consumption of $4 \mathrm{~kW}$.

Fig. 12 shows the power loss between the conventional boost converter and the dual boost converter at a given load variations. The power loss for each PFC boost converter increases as the output load increases. In terms of power losses, the proposed PFC converter shows much lower power losses then the conventional PFC converter.

Fig. 13 show the input power consumption and input power factor based on operating frequency of the compressor motor. It can be confirmed that input power factor is above that $95 \%$ at all operating frequency of compressor motor.

Fig. 14 shows the experimental results according to harmonic current regulations for DC inverter air conditioner, and it is confirmed that all of the required conditions and regulations are met.

Fig. 15 shows PCB developed for DC inverter air conditioner. Manufacturing time is reduced due to inductors built-

TABLE II

SPECIFICATIONS OF PROPOSED DC INVERTER CONTROL SYSTEM.

\begin{tabular}{|l||c|c|}
\hline & unit & range \\
\hline \hline AC input voltage & $V$ & $220 \sim 240$ \\
\hline inductor & $\mu H$ & 240 \\
\hline reference DC-link voltage & $V$ & 380 \\
\hline maximum power & $k W$ & 4 \\
\hline DC-link capacitor & $\mu F$ & 2040 \\
\hline switching frequency & $k H z$ & 40 \\
\hline
\end{tabular}




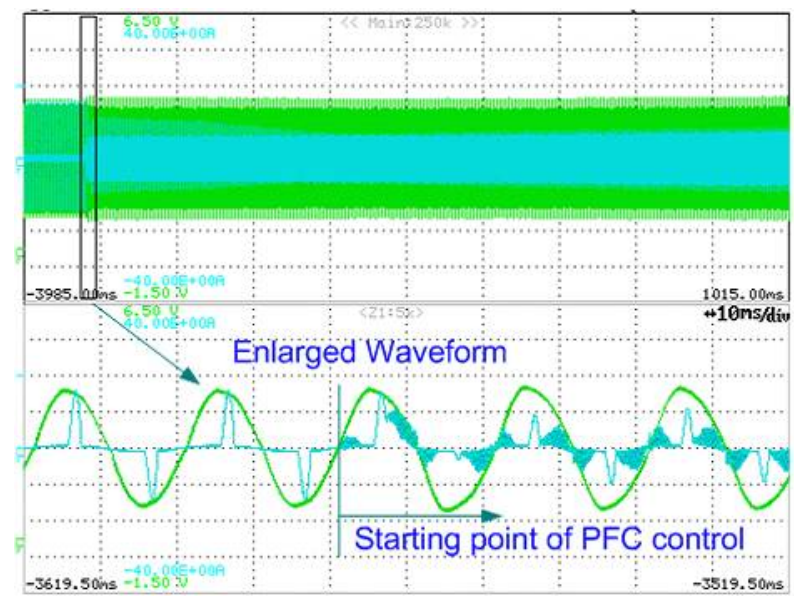

Fig. 9. Input current waveform before and after applying PFC control.

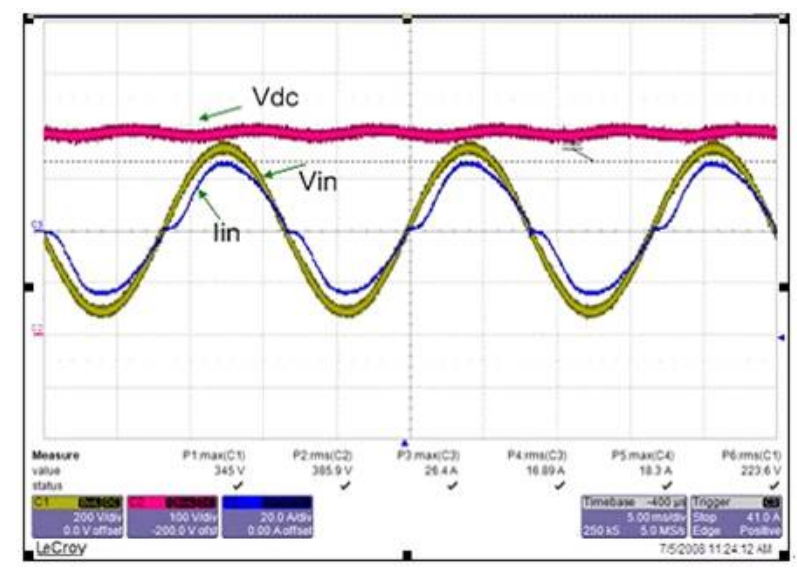

Fig. 10. Experimental waveforms performed by PFC control; DC-link voltage, input voltage, and input current.

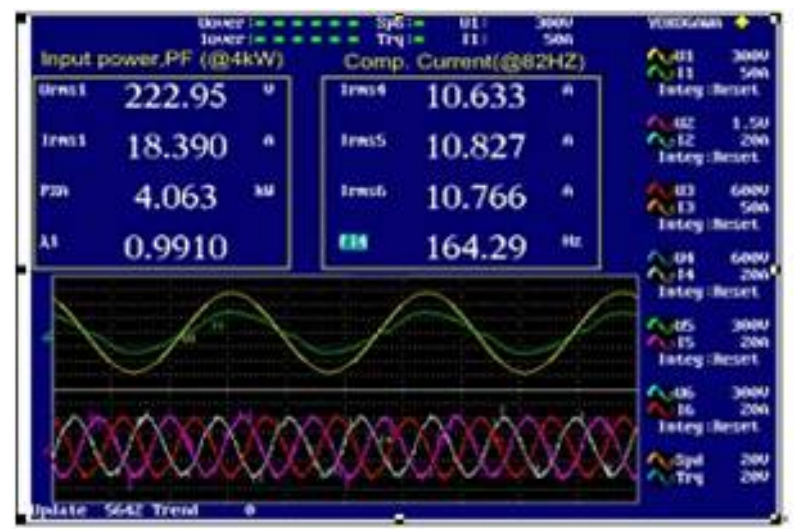

Fig. 11. Experimental power analyzed data under given $4 k W$ DC inverter control system; input current, input power factor, compressor phase current, and compressor operating frequency.

in on PCB. Controller reliability is increased by modularizing power components.

\section{CONCLUSIONS}

In this paper, a cost-competitive $4 k W \mathrm{DC}$ inverter control system for air conditioner is implemented using high-speed microprocessor. It also describes the design of a single-phase

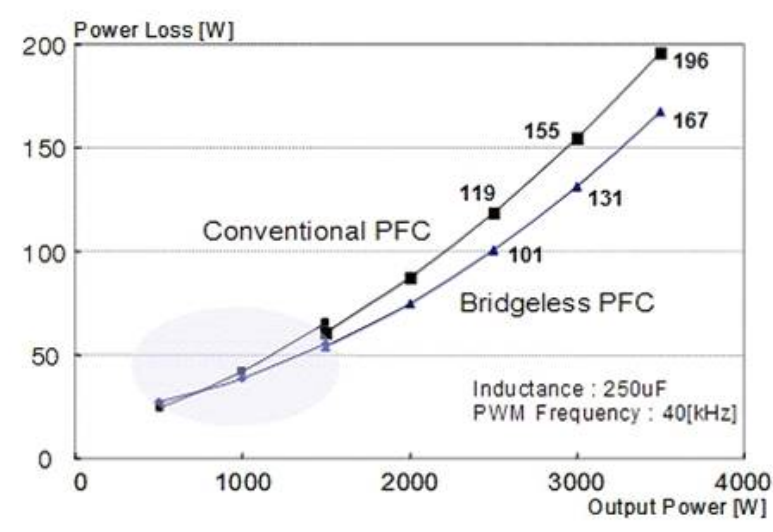

Fig. 12. Power loss comparison according to PFC topologies.

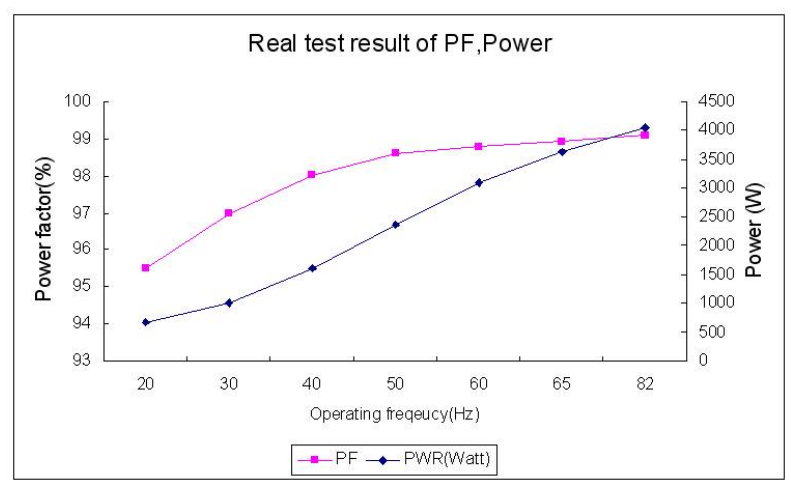

Fig. 13. Input power and power factor according to operating frequency of compressor.

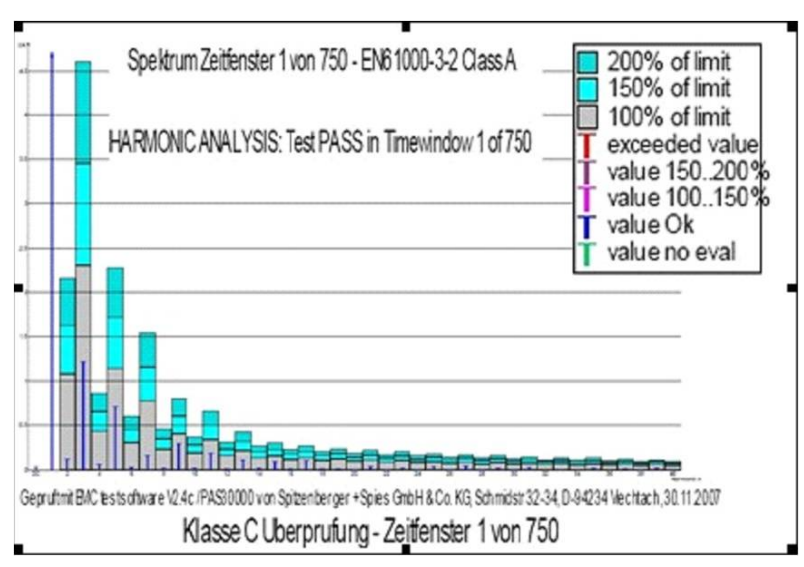

Fig. 14. Satisfied experimental results according to harmonic current regulations for DC inverter air conditioner.

PFC dual boost converter for DC inverter air conditioner. The controller's reliability and quality are verified through experiments. The differentiated performances in this paper are as follows.

- Reliability improvement of electronic components through PFC modularization to improve the reliability of control system

- Elimination of voltage sensors by estimating input voltage required for PFC control through feedbacked current information. 


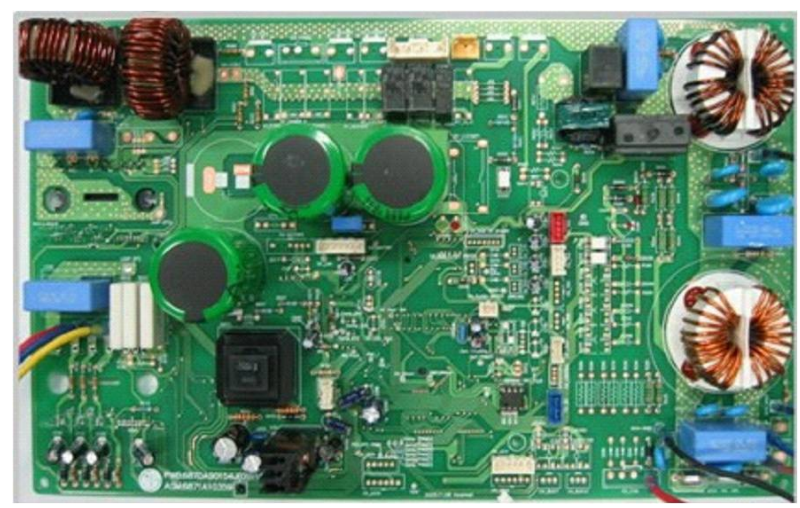

Fig. 15. Prototype of DC inverter control system.

- Improvement of mass-production by selecting inductor with high flux core, which can be largely minimized and easily build on PCB, and high speed switching of dual boost converter

- Robust controller implementation for DC-link voltage regulation in the case of variable load conditions

- Increase of air conditioner heating capacity in the case of lower temperature, enabling compressor IPMSM to drive in high speed regions by boosting DC-link voltage

- Maximum reduction of $17 \%$ power loss according to consumption power, compared to conventional scheme

- Satisfied input power factor $(95 \% \sim 99 \%)$ and lower input current harmonics under load conditions

\section{REFERENCES}

[1] Haoyi Ye, Zhihui Yang, Jingya Dai, Chao Yan, Xiaoni Xin, and Jianping Ying, "Common Mode Noise Modeling and Analysis of Dual Boost PFC Circuit," in Proceedings of INTEELEC, pp.575-58, 2004.

[2] M. Malinowski, M.P. Kazmierkowski, W. Szczygiel, and S. Bernet, "Simple Sensorless Active Damping Solution for Three-Phase PWM Rectifier with LCL Filter," in Proceedings of IEEE IECON, pp.987-991, 2005.

[3] Kyu-Min Cho,Byung-Gyu Ryu, and Gun-Woo Moon, "Bridgeless High Efficiency ZVZCS Power Factor Correction Circuit for PDP Power Module," Journal of Power Electronics, Vol.10, No.3, pp.226-232, Jun. 2005.

[4] Jeong-Kyu Ju, Tae-Young Ahn, Pyung-Woo Jang, In-Bum Jeong, and Gwang-Bo Choi, "A Study on the 1kW Class Boost Converter for PFC Using a MPP Core," Journal of Power Electronics, pp.781-783, Jul. 2002.

[5] L. Huber, Yungtaek Jang, and M.M. Jovanovic, "Performance Evaluation of Bridgeless PFC Boost Rectifiers," IEEE Trans. on Power Electronics, Vol. IA-23, Issue 3, pp.1381-1390, May 2008.

[6] Y. Li and T. Takahashi, "A Digitally Controlled 4-kW Single-Phase Bridgeless PFC Circuit for Air Conditioner Motor Drive Applications," in Proceedings of IPEMC, pp.1-5, 2006.
[7] Dong-Choon Lee and Young-Sin Kim, "Control of Single-Phase-toThree-Phase AC/DC/AC PWM Converters for Induction Motor Drives," IEEE Trans. on Industrial Electronics, Vol.54, Issue 2, pp.707-804, April 2007.

[8] H.O. Aintablian and H.W. Hill, "A New Single Phase to Three Phase Converter with Active Input Current Shaping for Low cost AC Motor Drives," in Proceedings of IECON, pp.452-457, Sept. 1994.

[9] R. Srinivasan and R. Oruganti, "A Unity Power Factor Converter Using Half-Bridge Boost Topology," IEEE Trans. on Power Electronics, Vol.13, Issue 3, pp.487-500, May 1998.

[10] A.H. Mitwalli, S.B. Leeb, G.C. Verghese, and V.J. Thottuvelil, "An Adaptive Digital Controller for a Unity Power Factor Converter," IEEE Trans. on Power Electronics, vol.11, Issue 2, pp.374-382, March 1996.

[11] S. Hansen, M. Malinowski, F. Blaabjerg, and M.P. Kazmierkowski, "Sensorless Control Strategies for PWM Rectifier," in Proceedings of APEC, pp.832-838, 2000.

[12] I. Ando, I. Takahashi, and K. Utsunomiya, "A Simple Sensorless Method for Sinusoidal PWM Converters," in Proceedings of PCC-Nagaoka, pp.241-246, 1997.

[13] T. Noguchi, H. Tomiki, S, Kondo, and I. Takahashi, "Direct Power Control of PWM Converter without Power-Source Voltage Sensor," IEEE Trans. on Industry Applications, Vol.34, No.3 pp.473-479, 1998.

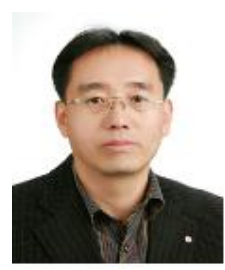

Gwi-Geun Park received his B.S in Electronics Engineering from Kyungnam University, Gyeongnam, Korea, in 1990 and his M.S in Intelligent Machinery System, Pusan National University, Busan, Korea, in 2006. He is currently researching toward his Ph.D. in Intelligent Machinery System, Pusan National University, Busan, Korea. Since 1990, he has been working as Chief Research Engineer at LG Electronics Inc. His current research interests incldue the control of electrical machines, control of power converters, motor drives and the control of inverter air conditioners.

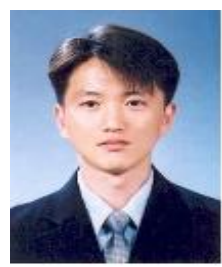

Kee-Yong Kwon received his B.S. in Electrical Engineering from Gyeongsang National University, Jinju, Korea, in 2000 and his M.S. in Electronic Engineering from Kyungpook National University, Daegu, Korea, in 2002, Since 2000, he has served as Senior Research Engineer at LG Electronics Inc. He is engaged in research on stability and control of synchronous machines, and control of air conditioning system.

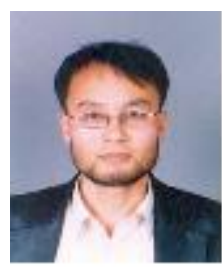

Tae-Woong Kim received his B.S. and M.S. in Electrical Engineering from Chungbuk National University, Chungbuk, Korea, in 1990 and 1993, respectively. He received his Ph.D. from Yokohama National University, Japan, in 1996. He joined the Yaskawa Electric Corporation, Japan, from April 1996 to September 2001 He was a Research Associate Professor for one year at Aalborg University, Denmark. Later, he joined the faculty of Gyeongsang National University, Jinju, Korea, in October 2002, where he is presently an Associate Professor in the Department of Control and Instrumentation Engineering. His research interests include power electronics, motion control, electric vehicles, renewable energy, and applied embedded control systems. Dr. Kim is an active member of KIPE, IEEE, IEEJ, GNU-RICIC, and GNU-ERI. He received the IEEE IE Transaction Best Paper Award in 2000 and the outstanding academic co-work project award from LG Electronics DAC Lab in 2008. 